\title{
Effects of paradigm and inter-stimulus interval on age differences in eyeblink classical conditioning in rabbits
}

\author{
Diana S. Woodruff-Pak, ${ }^{1}$ Susan E. Seta, LaToya A. Roker, and Melissa A. Lehr \\ Department of Psychology, Temple University, Philadelphia, Pennsylvania 19122, USA
}

\begin{abstract}
The aim of this study was to examine parameters affecting age differences in eyeblink classical conditioning in a large sample of young and middle-aged rabbits. A total of 122 rabbits of mean ages of 4 or 26 mo were tested at inter-stimulus intervals (ISIs) of 600 or $750 \mathrm{msec}$ in the delay or trace paradigms. Paradigm affected both age groups dramatically, with superior performance in the delay paradigm. ISI was salient as middle-aged rabbits were significantly impaired in 750-msec compared with 600 -msec delays, and young rabbits were significantly less impaired in 600-msec than in 750-msec trace. Young rabbits performed equally well at both delay ISIs, and consequently, there were significant age differences in 750-msec but not in 600-msec delays. Middle-aged rabbits performed poorly at both 600- and 750-msec trace, resulting in significant age differences in 600-msec but not in 750-msec trace. Timing of the conditioned response has been associated with cerebellar cortical function. Normal aging of the cerebellar cortex likely contributed to the magnitude of the effect of ISI in delay conditioning in middle-aged rabbits. Results demonstrate that the magnitude of age differences in eyeblink conditioning can be enlarged or eliminated by ISI and paradigm.
\end{abstract}

Eyeblink classical conditioning is impaired relatively early in the life span of mammals, with age differences appearing at $\sim 24$ mo in rabbits (Solomon and Groccia-Ellison 1996; Thompson et al. 1996) and between 40 and $50 \mathrm{yr}$ in humans (Woodruff-Pak and Thompson 1988; Solomon et al. 1989). Rabbit life expectancy is $8 \mathrm{yr}$, with life span reported as long as $14 \mathrm{yr}$. Failing reproductive capacity in female breeder rabbits around $18-24$ mo has been used as a biological marker of middle age for this species. The fact that age-related impairment in eyeblink conditioning begins in middle age in rabbits and humans, coupled with the striking parallels between rabbits and humans in behavioral and neurobiological substrates, have made eyeblink classical conditioning in the rabbit an attractive model system for the study of agerelated memory impairment.

Most studies of age differences in eyeblink conditioning in rabbits have involved comparisons of small samples of different age groups in a single paradigm at a single inter-stimulus interval (ISI). Our knowledge about age-related deficits by paradigm and ISI is based on a collection of relatively low powered studies using various ISIs and paradigms carried out at different times by different laboratories with different equipment and procedures. Consequently, there are some inconsistencies in the research literature. For example, the first study on eyeblink conditioning and aging reported significant age differences in short-ISI $(<500$ msec) delay eyeblink conditioning (Powell et al. 1981), but another early study reported the absence of age differences in shortISI delay (Graves and Solomon 1985). One aim of the present study was to compare paradigms and ISIs in different age groups of rabbits tested around the same time by the same experimenters in the same laboratory. We used a balanced design of the same ISIs in two paradigms in a sample size with high statistical power. A minimum of 10 young or middle-aged rabbits were tested in each group at ISIs of 600 or $750 \mathrm{msec}$ in either the delay

\footnotetext{
'Corresponding author.
}

E-mail pak@temple.edu; fax (215) 204-5539.

Article is online at http://www.learnmem.org/cgi/doi/10.1101//m.504107. or trace eyeblink conditioning paradigms or in an explicitly unpaired control condition.

\section{Delay and trace eyeblink conditioning and their substrates}

In the delay paradigm, a neutral stimulus such as a tone conditioned stimulus (CS) is presented approximately half a second before the onset of a corneal airpuff eyeblink-eliciting unconditioned stimulus (US). The organism learns to blink to the tone CS before the onset of the airpuff US, and the learned response is called the conditioned response (CR). In the trace paradigm, the CS is presented and then turned off, and a blank period ensues before the onset of the US. The blank period is called the "trace." In the explicitly unpaired control condition, the tone and airpuff are never paired. They are presented independently in a random sequence to control for possible differences in nonassociative effects such as sensitization, habituation, or motor responding. In this study, the explicitly unpaired condition was used to control for age differences in nonassociative effects.

The amount of time between CS onset and US onset, the ISI, affects performance. In eyeblink classical conditioning studies in rabbits, ISIs of $250-750 \mathrm{msec}$ are the most common, with the most rapid conditioning occurring between 250 and $500 \mathrm{msec}$. Extending the ISI beyond $500 \mathrm{msec}$ increases the difficulty level in rabbits. The trace paradigm extends the ISI in addition to inserting the blank trace period. Thus, it increases difficulty in two ways. Schneiderman (1966) compared the delay and trace eyeblink conditioning paradigms in young adult rabbits at the same ISIs $(250,500,1000$, and $2000 \mathrm{msec})$ and found a highly significant effect of paradigm. There was a higher level of conditioning in the delay than in the trace paradigm.

The cerebellum is essential in all eyeblink classical conditioning paradigms (for review, see Christian and Thompson 2003), including the 750-msec trace conditioning paradigm (Woodruff-Pak et al. 1985; Pakaprot and Thompson 2005). The trace paradigm is called "hippocampus dependent" because rabbits with bilateral lesions of the hippocampus do not acquire CRs 
when the trace period exceeds 300 msec (Moyer et al. 1990). In rabbits, bilateral removal of the hippocampus does not impair delay eyeblink conditioning (Schmaltz and Theios 1972), even in the long 750-msec delay paradigm in middle-aged rabbits (Woodruff-Pak et al. 1997). Another aim of the present study was to relate known neurobiological substrates of ISI, paradigm, and normal aging to the behavioral results. In this manner, we were using age-related deficits in eyeblink classical conditioning to look into neural substrates.

Age-associated deficits in the delay and trace paradigms A review of the research literature on age and eyeblink classical conditioning indicated that age-associated deficits are relatively small in the short-ISI delay paradigm for 24- to 36-mo-old rabbits but may increase rapidly beyond 36 mo of age (Green and Woodruff-Pak 2000). In one of the few large studies of normal aging and eyeblink conditioning in rabbits, Solomon and Groccia-Ellison (1996) compared 96 rabbits in four different age groups in the 400-msec and 900-msec delay and 900-msec trace (500-msec CS, 400-msec trace interval) paradigms. There were eight rabbits/group tested at the mean ages of 6, 24, 36, or 48 mo in one of the three paradigms. Young rabbits reached an asymptote of $\sim 80 \%$ CRs by session 5 in 400 -msec delay and $\sim 75 \%$ CRs by session 5 in 900-msec delay. In contrast, 24- and 36-mo old rabbits reached an asymptote of $\sim 60 \%$ CRs by sessions $5-7$ in 400-msec delay, and these groups took several more sessions of training to reach the same level of learning at 900-msec delay. By far, the greatest impairment was observed in 48-mo-old rabbits that attained $\sim 30 \%$ CRs after nine sessions of training in 400 msec delay and $<10 \%$ CRs after 10 sessions in 900-msec delay. Age-related deficits appeared at younger ages as the ISI was lengthened.

The "blank" trace period makes eyeblink conditioning much more difficult for both young and older rabbits, and they acquire CRs more slowly than in the delay paradigm. In 900msec trace, 6-mo-old rabbits never attained more than a mean of $\sim 55 \%$ CRs, and 24- and 36-mo-old rabbits never produced more than a mean of 30\% CRs (Solomon and Groccia-Ellison 1996). Forty-eight-month-old rabbits in that study never exceeded a mean of $20 \%$ CRs in the 900 -msec trace paradigm.

The other large study of normal aging and eyeblink conditioning was reported by Thompson et al. (1996), who tested a total of 174 rabbits ranging in age from 2-36 mo. Most rabbits in this study were used to assess the effect of age on trace conditioning, although 18 young rabbits (six rabbits/group) were tested to compare short and long-ISI delay and trace. Using a 100 -msec tone CS and a 500-msec trace, even young rabbits were significantly slower to acquire CRs in trace than delay. Statistically significant age differences in the 600 -msec trace paradigm appeared by 24 mo of age. Given that auditory acuity declines with age in many mammalian species, a short-duration 100-msec tone CS might have confounded age-related hearing impairment with age-related learning impairment in this study. Nevertheless, the large, high-powered studies of age and eyeblink conditioning provide general agreement that rabbits begin to show ageassociated declines in the trace paradigm at $\sim 24$ mo (Solomon and Groccia-Ellison 1996; Thompson et al. 1996). However, neither study compared different ISIs in the trace paradigm.

The two large published studies of eyeblink conditioning and aging in rabbits focused on 400- and 900-msec delay and 900-msec trace (Solomon and Groccia-Ellison 1996) or 600-msec trace with a 100-msec CS and 500-msec trace interval (Thompson et al. 1996). Research in our laboratory has focused on the 750msec delay paradigm that is sensitive to age-related learning impairment in rabbits by 24 mo (e.g., Woodruff-Pak et al. 2001). We aimed to compare this paradigm to a trace paradigm with a com- parable ISI and a 500-msec trace interval in young and older rabbits. In rabbits, the hippocampus is essential when the trace interval is $500 \mathrm{msec}$, but not when the trace interval is $300 \mathrm{msec}$. (Moyer et al. 1990). Behavioral data indicate that the hippocampus becomes essential in rabbits when the trace interval is 400 msec (Rose et al. 2007). Thus, we chose the 600-msec trace paradigm with a 400-msec trace interval and matched it with a 600msec delay for comparisons to delay and trace at the $750-\mathrm{msec}$ ISI. Previous research led us to predict that there would be significant age differences in the 750-msec delay paradigm, and we expected to observe significant age differences in the more difficult 750-msec trace paradigm. We found no data on age differences in the 600-msec delay paradigm, and previous research on age differences in shorter ISI delay paradigms was inconsistent. Our only prediction about performance in the $600-\mathrm{msec}$ delay and trace paradigms was that rabbits would be more impaired in trace than in delay.

\section{Results}

\section{Paired presentations of CS and US}

All but 10 of the young rabbits in this study were female, and all older rabbits were female. In young organisms, sex differences in eyeblink conditioning have not been observed. A $2(\mathrm{Sex}) \times 10$ (Training Sessions) repeated-measures ANOVA using the dependent measure of percentage of CRs indicated that there was not a statistically significant effect of sex or a significant sex by training sessions interaction effect. Because there were no sex differences between young male and female rabbits tested in the 750msec trace paradigm, data from these groups were combined to form the young 750-msec trace group.

A 2 (Age) $\times 2$ (ISI) $\times 2$ (Paradigm) $\times 10$ (Training Sessions $)$ repeated-measures ANOVA was carried out using the dependent measure of percentage of CRs (Fig. 1A). There were statistically significant main effects of Age $\left(F_{(1,94)}=5.08, P=0.027\right)$, ISI $\left(F_{(1,94)}=6.36, P=0.013\right)$, Paradigm $\left(F_{(1,94)}=114.18, P<0.001\right)$, and Training Sessions $\left(F_{(9,846)}=94.81, P<0.001\right)$. The interaction effects that achieved statistical significance were the Age $\times$ ISI $\times$ Paradigm effect $\left(F_{(1,94)}=4.31, P=0.041\right)$, the ISI $\times$ Training Sessions effect $\left(F_{(9,846)}=2.87, P=0.002\right)$, the Paradigm $\times$ Training Sessions effect $\left(F_{(9,846)}=24.45, P<0.001\right)$, and the ISI $\times$ Paradigm $\times$ Training Sessions effect $\left(F_{(9,846)}=2.00\right.$, $P=0.036)$.

Partial Eta squared $\left(\mathrm{h}_{\mathrm{p}}{ }^{2}\right)$ was used as the measure of effect size to evaluate the strength of association between the main effects of Age, ISI, Paradigm, and Training Sessions and the dependent measures. Among the between-subjects main effects, Paradigm had the greatest effect size, $\mathrm{h}_{\mathrm{p}}{ }^{2}=0.548$. The magnitude of the effect of Paradigm is evident when the data are averaged over the 10 training sessions to show mean total percentage of CRs with analysis of the significant Age $\times$ ISI $\times$ Paradigm interaction (Fig. 1B). The effect sizes were much smaller for ISI $\left(\mathrm{h}_{\mathrm{p}}{ }^{2}=0.063\right)$ and Age $\left(\mathrm{h}_{\mathrm{p}}{ }^{2}=0.051\right)$. For within-subjects variables, Training Sessions had a large effect size, $\mathrm{h}_{\mathrm{p}}{ }^{2}=0.502$, that is evident in the acquisition curves in Figure $1 \mathrm{~A}$.

Results from the dependent measure CR amplitude were somewhat comparable, although percentage of CRs was more sensitive to differences between the groups. A 2 (Age) $\times 2$ $($ ISI) $\times 2$ (Paradigm) $\times 10$ (Training Sessions) repeated-measures ANOVA indicated statistically significant main effects of Paradigm $\left(F_{(1,94)}=47.05, P<0.001\right)$ and Training Sessions $\left(F_{(9,846)}=25.30, P<0.001\right)$ (Fig. $\left.2 \mathrm{~A}\right)$. The Paradigm $\times$ Training Sessions interaction effect was also significant $\left(F_{(9,846)}=9.53\right.$, $P<0.001)$. With CR amplitude data, Paradigm had the greatest effect size, $h_{p}{ }^{2}=0.334$. The magnitude of this effect is evident when the data are averaged over the 10 training sessions to show 


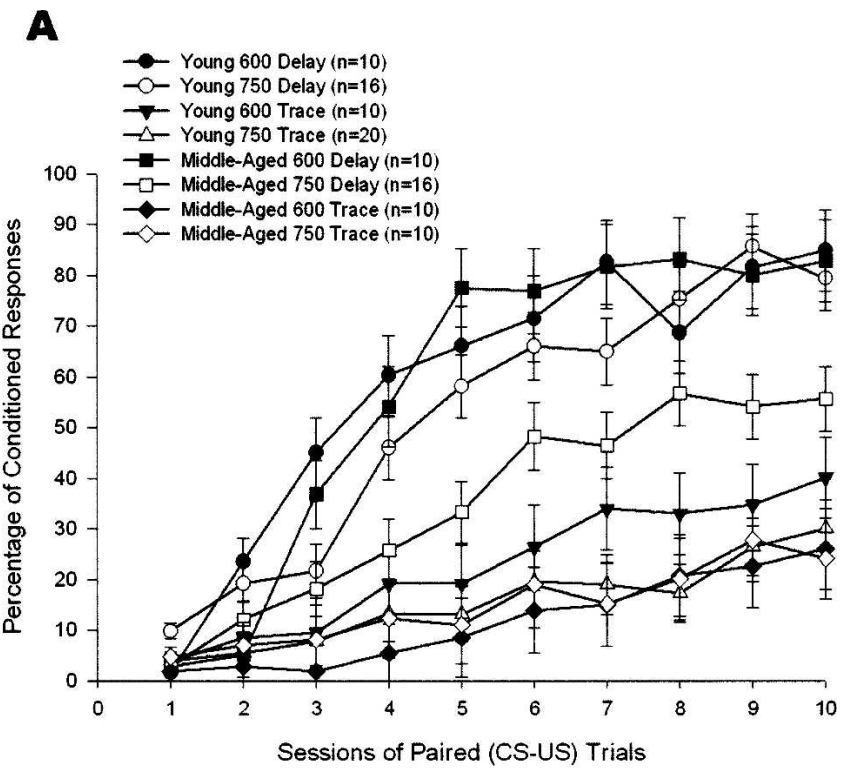

$\mathbf{B}$

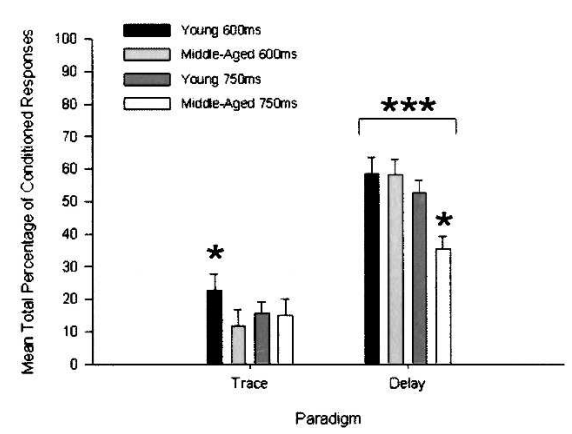

Figure 1. (A) Percentage of conditioned responses (CRs) in 102 4- and 26-mo-old rabbits that received 90 paired presentations of tone conditioned stimulus and corneal airpuff unconditioned stimulus for 10 training sessions in the 600 - or $750-\mathrm{msec}$ delay or trace eyeblink classical conditioning paradigms. (B) Percentage of CR data presented in $A$ averaged over 10 sessions and compared with analysis of the significant effects. The difference in percentage of CRs between the delay and trace paradigms was significant beyond the $0.001{ }^{* * *}$ level of confidence. Percentage of CRs were significantly lower in middle-aged rabbits in 750msec delay at the $0.05\left(^{*}\right)$ level and were significantly higher in young rabbits in 600-msec trace at the $0.05\left(^{*}\right)$ level. Error bars, SEM.

mean total CR amplitude (Fig. 2B). The effect size of ISI and Age were much smaller, $\mathrm{h}_{\mathrm{p}}{ }^{2}=0.002$ and 0.002 , respectively. For within-subjects variables, Training Sessions had an effect size of $\mathrm{h}_{\mathrm{p}}{ }^{2}=0.212$.

Response latency is the time from CS onset to the first response of $\geq 0.5 \mathrm{~mm}$. Response latency was analyzed separately for the 600 - and 750-msec paradigms. A 2 (Age) $\times 2$ (Paradigm) $\times 10$ (Training Sessions) repeated-measures ANOVA for the 600-msec ISI indicated statistically significant main effects of Para$\operatorname{digm}\left(F_{(1,36)}=139.09, P<0.001\right)$ and Training Sessions $\left(F_{(9,324)}=35.65, P<0.001\right)$ (Fig. 3A). The Paradigm $\times$ Training Sessions interaction effect was also significant $\left(F_{(9,324)}=9.53\right.$, $P<0.001)$. Paradigm had the greatest effect size, $\mathrm{h}_{\mathrm{p}}{ }^{2}=0.794$. The effect size of Age was much smaller, $\mathrm{h}_{\mathrm{p}}{ }^{2}=0.021$. Training Sessions had an effect size of $\mathrm{h}_{\mathrm{p}}{ }^{2}=0.498$. A 2 (Age) $\times 2$ (Paradigm) $\times 10$ (Training Sessions) repeated-measures ANOVA for the 750-msec ISI indicated statistically significant main effects of Paradigm $\left(F_{(1,58)}=38.37, P<0.001\right)$ and Training Sessions
$\left(F_{(9,522)}=34.74, P<0.001\right)$ (Fig. 3B). The effect of Age did not attain statistical significance at the 0.05 level of confidence $\left(F_{(1,58)}=3.58, P=0.063\right)$. The Age $\times$ Paradigm interaction was $\operatorname{significant}\left(F_{(1,58)}=5.51, P=0.022\right.$, $)$ as was the Paradigm $\times$ Training Sessions interaction effect $\left(F_{(9,522)}=9.50\right.$, $P<0.001)$. Paradigm had the greatest effect size, $\mathrm{h}_{\mathrm{p}}{ }^{2}=0.398$. The effect size of Age was $h_{p}{ }^{2}=0.058$. Training Sessions had an effect size of $\mathrm{h}_{\mathrm{p}}^{2}=0.375$.

Trials to learning criterion is the number of trials presented before a rabbit produces eight CRs in nine consecutive trials in a session of $\geq 40 \%$ CRs. This measure was compared in a 2 (Age) $\times 2$ (ISI) $\times 2$ (Paradigm) ANOVA. The effect of Age did not attain statistical significance at the 0.05 level of confidence $\left(F_{(1,94)}=2.96, P=0.089\right)$. There was a statistically significant effect of ISI $\left(F_{(1,94)}=5.41, P=0.022\right)$ and of Paradigm $\left(F_{(1,94)}=92.53, P<0.001\right)$. The Age $\times$ ISI $\times$ Paradigm interaction effect was also significant $\left(F_{(1,94)}=7.03, P=0.009\right)$ (Fig. 4). This significant interaction occurred because in young rabbits there was no difference between trials to learning criterion in 600- and 750-msec delay but a significant difference between

\section{A}

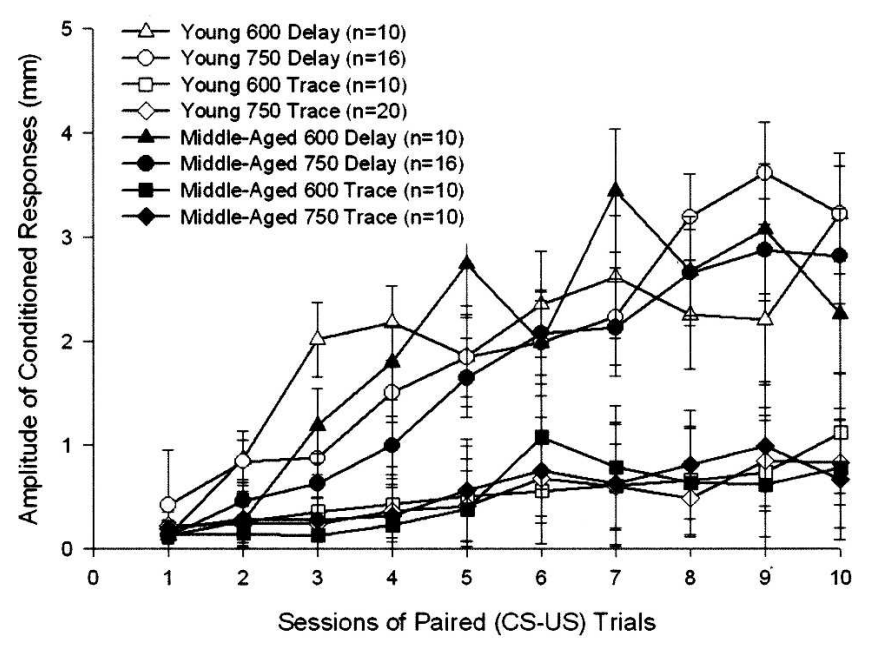

B

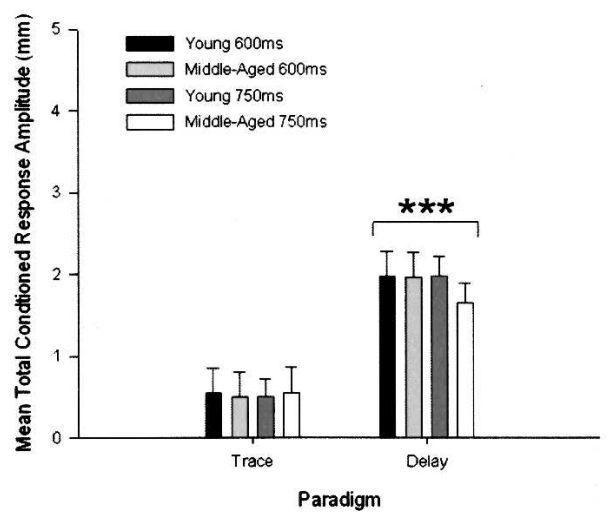

Figure 2. (A) Conditioned response (CR) amplitude in 102 4- and 26mo-old rabbits that received 90 paired presentations of tone conditioned stimulus and corneal airpuff unconditioned stimulus for 10 training sessions in the 600- or 750-msec delay or trace eyeblink classical conditioning paradigms. (B) CR amplitude data presented in $A$ averaged over 10 sessions and compared with analysis of the significant effects. The difference in CR amplitude between the delay and trace paradigms was significant beyond the $\left.0.001{ }^{(* *}\right)$ level of confidence. Error bars, SEM. 
A

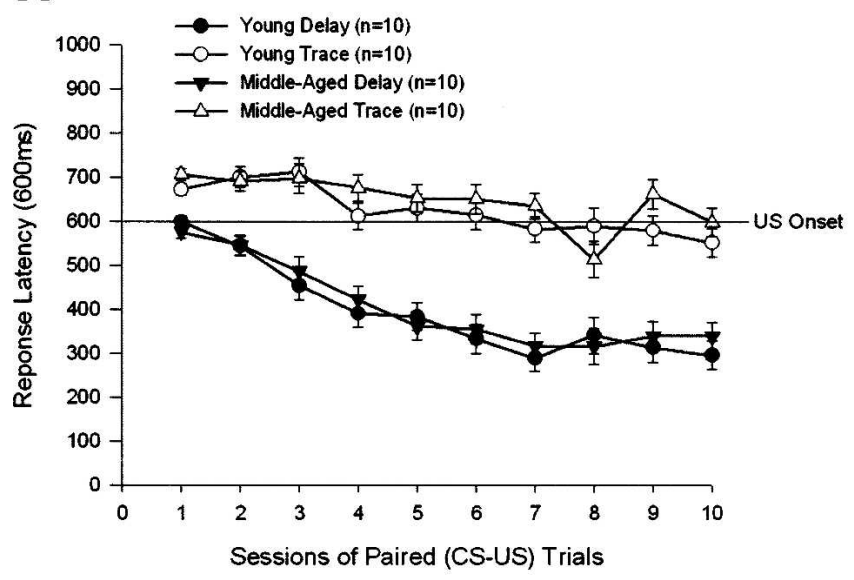

B

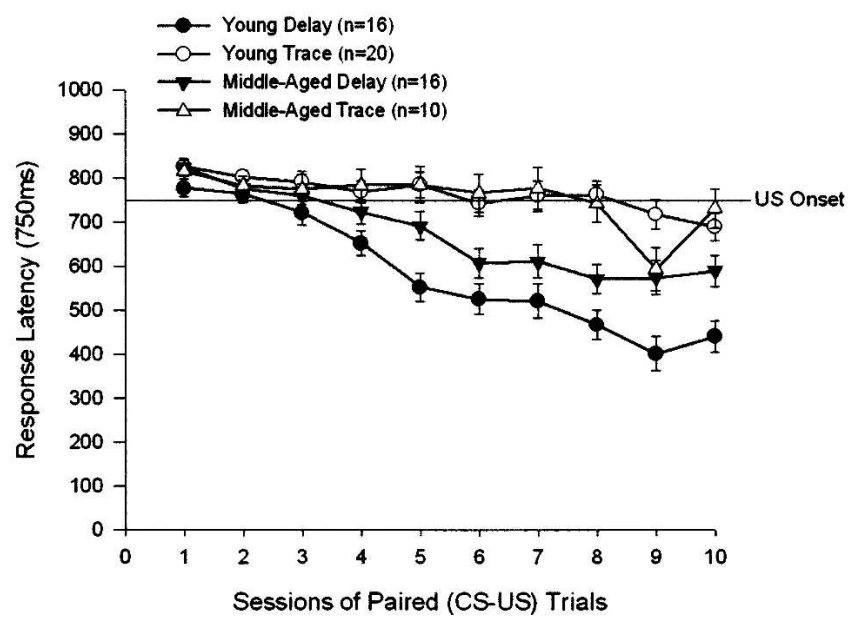

Figure 3. ( $A$ ) Response latency (latency to the first response $>0.5 \mathrm{~mm}$ ) in the 600-msec delay and trace paradigms in 40 4- and 26-mo-old rabbits that received 90 paired presentations of tone conditioned stimulus and corneal airpuff unconditioned stimulus for 10 training sessions in the 600-msec delay or trace eyeblink classical conditioning paradigms. The line showing unconditioned stimulus (US) for these paradigms is at $600 \mathrm{msec}$. Responses below the line are conditioned responses. (B) Response latency in the 750-msec delay and trace paradigms in 62 - and 26-mo-old rabbits that received 90 paired presentations of tone conditioned stimulus and corneal airpuff US for 10 training sessions in the 750-msec delay or trace eyeblink classical conditioning paradigms. The line showing US for these paradigms is at $750 \mathrm{msec}$. Error bars, SEM.

600- and 750-msec trace, whereas in middle-aged rabbits there was a significant difference between 600- and 750-msec delay but no difference between 600- and 750-msec trace.

The amplitude of the unconditioned response (UR) is a measure of the reflexive eyeblink to the corneal airpuff. Although it is a reflexive response, it is influenced by associative processes (Schreurs 2003). Presentation of the CS can facilitate the amplitude of the UR. Indeed, the first sign of conditioning in rabbits is exhibited in the amplitude of the UR (Weisz and McInerney 1990). A 2 (Age) $\times 2$ (ISI) $\times 2$ (Delay vs. Trace Paradigm) $\times 10$ (Training sessions) repeated-measures ANOVA was carried out using the dependent measure of UR amplitude. The main effects of ISI and Training Sessions were significant $\left(F_{(1,94)}=9.16\right.$, $P=0.003$ and $F_{(9,846)}=4.63, P<0.001$, respectively). The interaction effects of Training Sessions $\times$ Age $\left(F_{(9,846)}=2.42\right.$, $P=0.010)$, Training Sessions $\times$ Age $\times$ Paradigm $\left(F_{(9,846)}=2.31\right.$,
$P=0.015)$, and Training Sessions $\times$ ISI $\times$ Paradigm $\left(F_{(9,846)}=2.41\right.$, $P<0.011$ ) were also significant (Fig. 5A). As is typical in rabbit eyeblink conditioning, UR amplitude increased after the initial trials. This increase was greater in the middle-aged rabbits. UR amplitude was greater in the 750 -msec than the 600 -msec ISI (Fig. 5B).

\section{Explicitly unpaired presentations of CS and US}

Comparison of young and middle-aged rabbits in the explicitly unpaired paradigm indicated that age was not associated with differences in blinking after the tone CS onset (Responses in CS period) or in the magnitude of the UR (Fig. 6). A 2 (Age) $\times 10$ (Training Sessions) repeated-measures ANOVA comparing responses in the CS period had no significant main effects or interactions. Similarly, a 2 (Age) $\times 10$ (Training Sessions) repeatedmeasures ANOVA comparing UR amplitude had no significant main effects or interactions.

\section{Discussion}

Comparisons of large groups of young and middle-aged rabbits at the 600- and 750-msec ISI delay and trace eyeblink classical conditioning paradigms demonstrated that rabbits of a mean age of $26 \mathrm{mo}$ acquired CRs in the $600-\mathrm{msec}$ delay paradigm as well as 4-mo-old rabbits, but in the 750 -msec delay paradigm, the middle-aged rabbits were significantly impaired compared with young rabbits. The absence of a significant age effect at $600-\mathrm{msec}$ delay was not due to low power because there was a minimum of 10 rabbits per group in these comparisons. The observed power was in the medium range and was 0.607 for the effect of Age in the analysis of delay data. The observed power for the significant interaction between Age, ISI, and Paradigm was 0.538.

One component of the significant Age $\times$ ISI $\times$ Paradigm interaction effect was the fact that increasing the ISI from 600 to $750 \mathrm{msec}$ in the delay eyeblink conditioning paradigm did not affect the performance of young adult rabbits but resulted in significant impairment in middle-aged rabbits. The other component of this Age $\times$ ISI $\times$ Paradigm interaction effect was the dramatic difference in performance in trace compared with delay conditioning. For both age groups of rabbits, the trace paradigm was significantly more difficult than the delay paradigm. In the case of the young rabbits, conditioning was better in the 600msec compared with the 750-msec trace paradigm. For older rab-

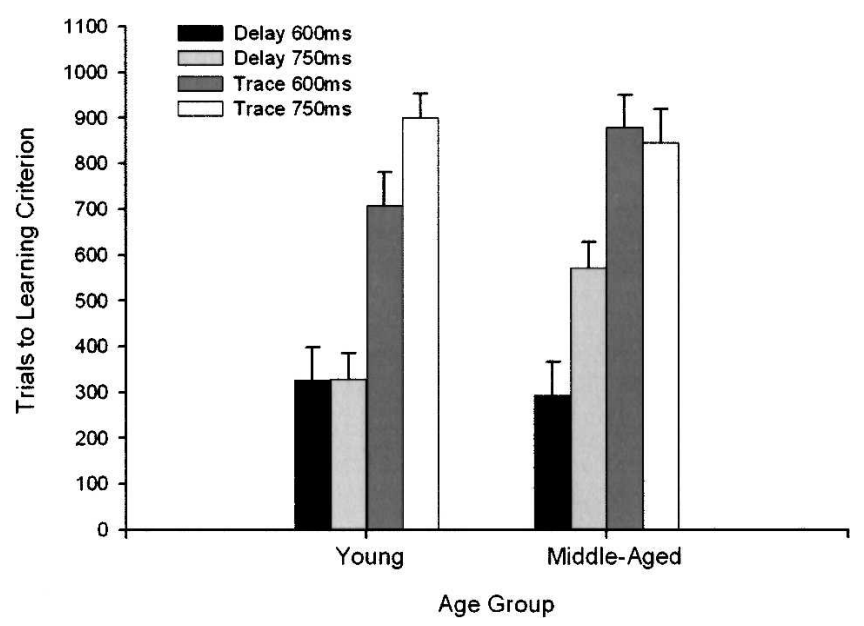

Figure 4. Trials to learning criterion in 102 4- and 26-mo-old rabbits that received 90 paired presentations of tone conditioned stimulus and corneal airpuff unconditioned stimulus for 10 training sessions in the 600 or 750-msec delay or trace eyeblink classical conditioning paradigms. Error bars, SEM. 


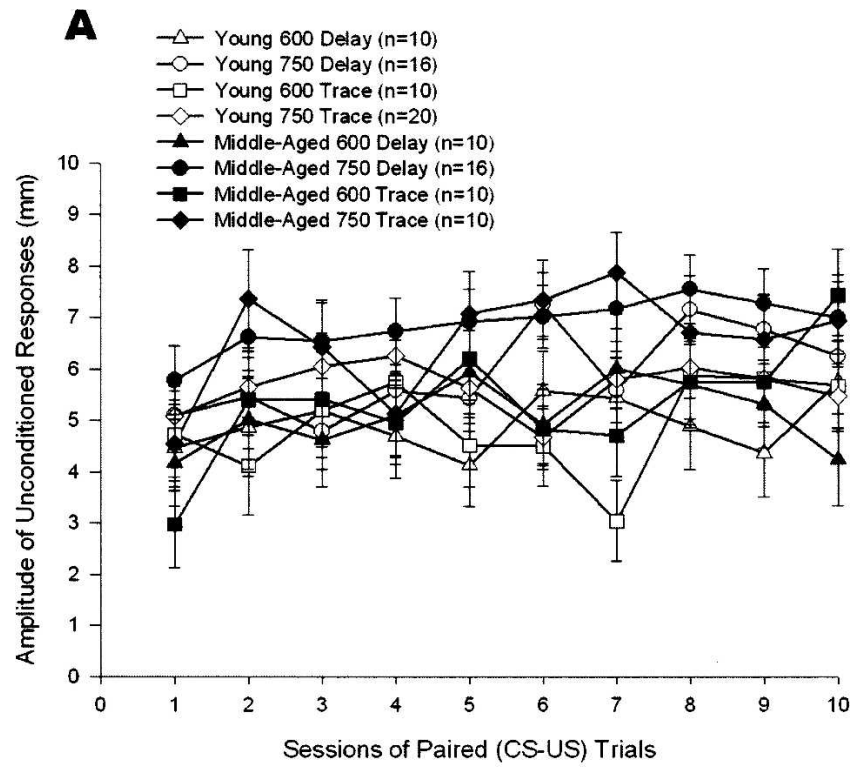

B

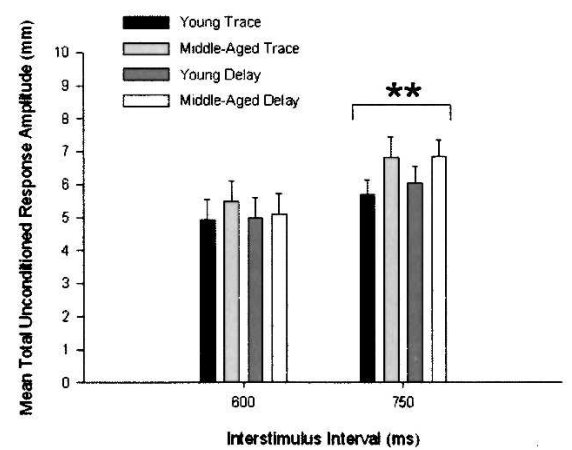

Figure 5. (A) Unconditioned response (UR) amplitude in 102 4- and 26-mo-old rabbits that received 90 paired presentations of tone conditioned stimulus and corneal airpuff unconditioned stimulus for 10 training sessions in the 600 - or $750-\mathrm{msec}$ delay or trace eyeblink classical conditioning paradigms. (B) UR amplitude data presented in $A$ averaged over 10 sessions. The difference in UR amplitude between the 600- and $750-\mathrm{msec}$ ISI was significant beyond the $\left.0.01{ }^{* *}\right)$ level of confidence. Error bars, SEM.

bits, acquisition was already at floor in the 600 -msec trace paradigm so performance was equally impaired in the 600- and 750msec trace paradigm. Control rabbits tested in the explicitly unpaired condition demonstrated no age differences in responses in the CS period or in UR amplitude, indicating that nonassociative factors did not contribute to age differences in eyeblink classical conditioning.

To the best of our knowledge, this is the only study in which a large sample of young and middle-age rabbits were compared in different trace paradigms. In this study, the trace interval was varied by $100 \mathrm{msec}$. It is documented in rabbits that the $500-\mathrm{msec}$ trace interval is hippocampus dependent and that the 300 trace interval is hippocampus independent (Moyer et al. 1990). We assume that the 400-msec trace interval is hippocampus dependent on the basis of the similarity in performance in middle-aged rabbits in the 600- and 750-msec trace paradigm (Rose et al. 2007), but no actual hippocampus ablation study has been carried out with the $400-\mathrm{msec}$ trace interval. It is likely that there would have been significantly better performance in young and middle-aged rabbits if a 300-msec trace interval had been used.
To equate the ISI between the delay and trace paradigms, there was a 50-msec difference between the CS in the two trace paradigms, with a $200-\mathrm{msec}$ CS in the $600-\mathrm{msec}$ trace paradigm and a $250-\mathrm{msec}$ CS in the 750-msec trace paradigm. For humans, the $20 \%$ difference between a 200 - and 250 -msec CS is difficult to perceive. This difference in CS duration probably did not affect the results, especially since performance differences between the two trace paradigms were small in comparison to the differences between the delay and trace paradigms.

The results of this study demonstrate that age differences in eyeblink conditioning can be magnified or eliminated depending upon the ISI and paradigm that are used. This information has utility for a variety of research strategies. For over a decade, we have used the 750-msec delay paradigm in rabbits a minimum of 24 mo of age to test cognition-enhancing drugs. Middle-aged rabbits take seven to nine daily 90 -trial sessions to acquire a criterion of eight CRs in nine consecutive trials in a session of $\geq 40 \%$ CRs. These seven to nine sessions provide a window of opportunity to show the efficacy of the drugs. It is more difficult to show drug efficacy in 4-mo-old rabbits because they attain criterion in three to four sessions. Ceiling effects are problematic in the 750msec delay paradigm in young rabbits. Floor effects are problematic in most trace paradigms in middle-aged and older rabbits. In the 10th training session in this study, middle-aged rabbits in the 600 -msec trace paradigm (200-msec CS, 400-msec trace) produced the highest mean number of CRs for any session that was only $26 \%$ CRs. It is more challenging to demonstrate a cognitionenhancing effect in this paradigm. Whereas three doses of a calcium-channel blocking drug showed some efficacy in the 750msec delay paradigm, only one dose showed efficacy in the 600msec trace paradigm (Rose et al. 2007). A criterion of $80 \%$ CRs in the $600-\mathrm{msec}$ trace paradigm with a $100-\mathrm{msec}$ CS and 500-msec trace was achieved by only two-thirds of the 24-mo-old rabbits and only $40 \%$ of 36 -mo-old rabbits (Thompson et al. 1996). In the $900-\mathrm{msec}$ trace paradigm with a $500-\mathrm{msec}$ CS and a $400-\mathrm{msec}$ trace, rabbits aged 24, 36, and 48 mo were equally impaired (Solomon and Groccia-Ellison 1996).

Just as there are circumstances in which it is desirable to exacerbate age differences, there are also circumstances when having young and older organisms perform at equal levels is desirable. To compare a treatment between young and older organisms, it would be advantageous to have them equal at a starting point. The 600-msec delay eyeblink classical conditioning

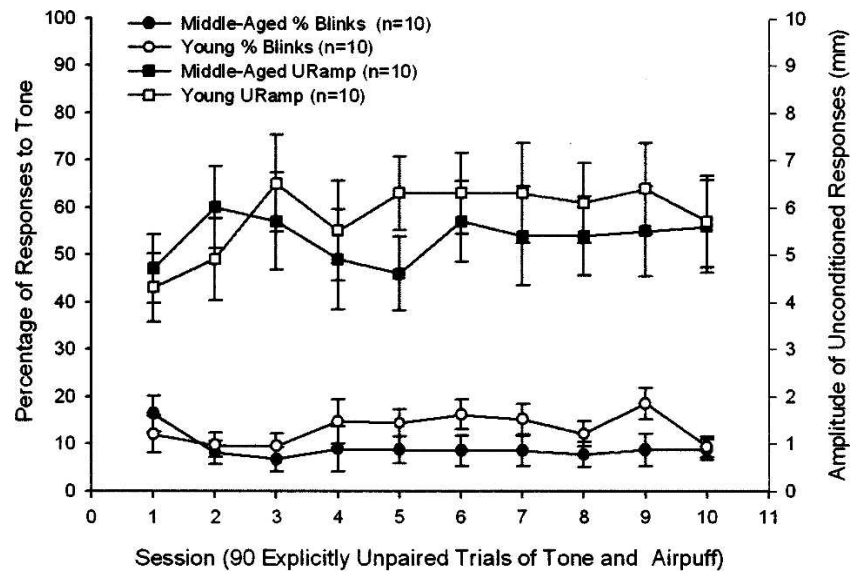

Figure 6. Responses in the conditioned stimulus (CS) period (left axis) are shown as the bottom two lines and unconditioned response amplitude (right axis) as the top two lines in 104 -mo-old and 10 26-mo-old rabbits tested in the explicitly unpaired condition. There were 10 training sessions with presentations of 45 tone and 45 corneal airpuff trials in a semi-random order. Error bars, SEM. 
paradigm would provide an opportunity to equalize the performance of young and middle-aged rabbits, as would the 750-msec trace paradigm. However, the investigators would need to address the issues of ceiling performance in the 600-msec delay paradigm and floor performance in the $750-\mathrm{msec}$ trace paradigm.

Over training sessions, there were differences in UR amplitude that were statistically significant. The change in UR amplitude over training sessions has been reported in many studies of eyeblink classical conditioning in rabbits and is anticipated (Weisz and McInerney 1990; Weisz and Walts 1990; Schreurs 2003). It has also been reported that UR amplitude is greater at longer than shorter ISIs in the delay and trace paradigms in rabbits (Weisz and Walts 1990). Longer ISIs result in greater UR amplitude in discrimination conditioning in rabbits (Canli et al. 1992) and humans (Marcos and Redondo 1999).

The effect of Age in these data was smaller than the effects of ISI or Paradigm. Rabbits tested in this study were a minimum of 24 mo old, with a mean age of 26 mo. Rabbit life expectancy is 8 yr, but reproductive capacity becomes impaired in female breeder rabbits between 18 and 24 mo. Previous research has demonstrated that modest age differences appear in 24-mo-old rabbits that are exacerbated by the time the rabbits are 48 mo of age (Woodruff-Pak et al. 1987; Solomon and Groccia-Ellison 1996). In the present study, even these "middle-aged" rabbits showed significant impairment when the ISI was extended from 600 to $750 \mathrm{msec}$ in the delay paradigm or compared with young rabbits in the $600-\mathrm{msec}$ trace paradigm. In both trace paradigms, performance was already at floor levels in 26-mo-old rabbits so that testing rabbits $>26$ mo would not show additional age-related impairment.

One aim of this study was to describe more fully age differences in eyeblink conditioning as a function of ISI. An interesting result was that in the 600 -msec delay paradigm, there were no age differences in conditioning. This result is consistent with previous research indicating no age differences between 4- and 24-mo-old rabbits in shorter (250 msec, $400 \mathrm{msec})$ ISI paradigms (Graves and Solomon 1985; Solomon and Groccia-Ellison 1996). This result is also consistent with research in human eyeblink conditioning. In 400-msec delay eyeblink classical conditioning, there are statistically significant impairments in middle age (Woodruff-Pak and Thompson 1988; Solomon et al. 1989; Woodruff-Pak and Jaeger 1998). These impairments are eliminated between young and middle-aged (but not older) adults in the 500-msec delay paradigm (Woodruff-Pak et al. 1999). Comparing life expectancy of rabbits and humans and using reproductive capacity as a biomarker, a 24-mo-old rabbit is comparable to a 40- to 50-yr-old human. Age differences in delay eyeblink classical conditioning appear in middle age in humans and rabbits, except at the most optimal ISIs.

Extending the ISI by $150 \mathrm{msec}$ from 600 to $750 \mathrm{msec}$ in the delay paradigm resulted in significant deficits in conditioning for older but not younger rabbits. The 750-msec ISI requires some mechanism that is affected by normal aging processes in middleaged rabbits. Data suggest that the cerebellar cortex is involved in the timing of CRs. Aspirations and electrolytic lesions in rabbit cerebellar anterior lobe (rostral cerebellar cortex) disrupted the timing of previously learned CRs in the delay paradigm (Garcia et al. 1999). When these rabbits were trained with a CS in a different sensory modality, they were unable to acquire CRs to that CS. The investigators concluded that induction of plasticity in the interpositus nucleus requires intact input from the cerebellar cortex. Electrophysiological recording of Purkinje neurons in the cerebellar anterior lobe of rabbits trained in a delay ISI discrimination paradigm identified many Purkinje neurons with significant learning-related activity (Green and Steinmetz 2005). These data also provided support for a role for the anterior cerebellar cortex in delay eyeblink classical conditioning. Patterns of pooled Purkinje neuron firing indicated excitation early in the trial that inhibited CR generation by inhibiting the deep cerebellar nuclei. During the later portion of a trial, CR generation was permitted through Purkinje neuron inhibition that disinhibited the cerebellar deep nuclei. Processes of normal aging may impair the fine-tuned patterning of Purkinje neuron firing even before old age.

Purkinje neurons are among the few neurons in the central nervous system exhibiting significant loss with normal aging (Larsen et al. 2000; Andersen et al. 2003). Using unbiased stereological techniques to estimate Purkinje neuron number in the cerebellar cortex, Woodruff-Pak (2006) found a loss of $36 \%$ by the age of $18 \mathrm{mo}$ in C57BL/6 mice, and Larsen et al. (2000) found an $11 \%$ loss by the age of 23 mo in Sprague-Dawley rats. In 26-mo-old rats, many Purkinje neurons appeared defoliated, with small distal dendrites and spiny branchlets being the most affected (Rogers et al. 1981). Related to the Purkinje neuron loss in these rats was a loss in synaptic density (Rogers et al. 1984). Electrophysiological studies identified a number of neuron firing parameters that were affected in normal aging in rats (Rogers et al. 1980). In particular, increasing numbers of aberrant, very slow-firing neurons were encountered in older animals. Agerelated dysfunction of the cerebellar $\beta$-adrenergic receptor was observed to affect spontaneous firing as well as modulating the effects of other neurotransmitters such as GABA (Bickford et al. 1985). Age-related Purkinje neuron loss in rabbit cerebellar cortex was estimated to be $23 \%$ by 14 mo and $40 \%$ by 48 mo (Coffin 1993), suggesting that age-related loss in Purkinje neurons in our 26-mo-old rabbits was significant. Age-related changes in the number and functional capacity of Purkinje neurons in cerebellar cortex may account for the significant impairment in acquisition in middle-aged rabbits in the 750-msec as compared to the 600msec delay eyeblink conditioning paradigm.

The difference between the delay and trace paradigm had the greatest effect size. In a series of studies using delay eyeblink classical conditioning in rabbits, it was observed that activity recorded in the CA1 pyramidal cell region of the hippocampus forms a predictive "model" of the amplitude-time course of the learned behavioral response, but only under conditions where behavioral learning occurs (Berger et al. 1976; Berger and Thompson 1978; Thompson et al. 1980). However, complete removal of the hippocampus bilaterally does not impair acquisition in delay eyeblink conditioning (Schmaltz and Theios 1972). The role of the hippocampus in delay eyeblink classical conditioning is called "modulatory" because manipulations of the hippocampus can impair or enhance the rate of acquisition. The memory trace itself is not in the hippocampus, but the hippocampus can markedly influence the storage process.

Although the hippocampus is not necessary for normal acquisition in the delay paradigm, it is necessary for trace eyeblink classical conditioning (Port et al. 1986; Solomon et al. 1986; Moyer et al. 1990; Kim et al. 1995; Kaneko and Thompson 1997). There is a long-lasting neuronal plasticity formed in the hippocampus following eyeblink conditioning. This change is essential for learning to occur in the trace eyeblink conditioning paradigm, at least until the learning is consolidated (Kim et al. 1995; Takehara et al. 2003).

Hippocampal pyramidal neurons in slices from rabbits trained in trace eyeblink conditioning showed a marked reduction in the slow after-hyperpolarization compared with neurons in slices from control animals that received explicitly unpaired presentations of the CS and US (Disterhoft et al. 1986). Afterhyperpolarization recorded in slice preparations from trained rabbits has also been observed in relation to normal aging (Disterhoft and McEchron 2000; Moyer et al. 2000). Aged CA1 neu-

\section{Learning \& Memory}

www.learnmem.org 
rons from learning-intact animals had significantly reduced postburst after-hyperpolarizations and reduced spike frequency adaptation (like those recorded in young rabbits), compared with neurons from control groups of naïve and aging rabbits that failed to learn. No differences were seen in resting potential characteristics after learning. The data suggest that postsynaptic excitability of CA1 neurons changes during acquisition of the hippocampus-dependent trace eyeblink conditioning in both young and older rabbits, with little of no change in excitability seen in learning-impaired older rabbits.

The fact that the trace paradigm increases the difficulty level for both young and middle-aged rabbits may be associated with the additional neural systems that are essential in trace conditioning. In addition to the cerebellum, an intact hippocampus (Solomon et al. 1986; Kim et al. 1995) and likely also an intact medial prefrontal cortex (Kornforst-Collins and Disterhoft 1998; Weible et al. 2000; Powell et al. 2001; Takehara et al. 2003) are essential for acquisition. Our data indicate that coordinating these systems that are impaired in normal aging results in performance in 26-mo-old rabbits that approaches floor levels, even in the 600-msec trace paradigm. Normal aging changes in firing properties of hippocampal neurons are associated with impaired performance in trace conditioning. These effects combine with age-related changes in the cerebellum to impair acquisition in the trace eyeblink classical conditioning paradigm.

\section{Materials and Methods}

\section{Study population: Rabbits}

A total of 122 specific pathogen-free (SPF) rabbits were used in this study. Fifty-six rabbits were female retired breeders of a mean age of $26.1(\mathrm{SD}=2.2)$ months and a mean weight of 4.1 $(\mathrm{SD}=0.4) \mathrm{kg}$. Sixty-six rabbits were young adults of a mean age of $4.2(\mathrm{SD}=0.8)$ months and a mean weight of $3.0(\mathrm{SD}=0.5) \mathrm{kg}$. Ten of the young rabbits were male, and 56 were female. All rabbits were purchased from Covance. They were individually housed in stainless steel cages in temperature and humidity controlled rooms in an Association for Assessment and Accreditation of Laboratory Animal Care International (AAALAC)-approved animal facility. They had ad libitum access to food and water during the experiment. The light/dark cycle was 12/12-h. The Institutional Animal Care and Use Committee (IACUC) at Temple University approved research procedures used in this study. This research was carried out in accordance with the Guide for the Care and Use of Laboratory Animals as adopted and promulgated by the National Institutes of Health.

\section{Study procedures}

The eyeblink classical conditioning paradigms tested using paired CS-US presentations were 600- and 750-msec delay and $600-$ and $750-$ msec trace. A total of 46 retired breeders and 56 young adult rabbits were tested in paired CS-US eyeblink conditioning. The explicitly unpaired condition used an 850-msec CS. A total of 10 retired breeders and 10 young adult rabbits were tested in the explicitly unpaired paradigm.

Over the course of seven days prior to training, the rabbits were gradually familiarized and adapted to Plexiglas restrainers for $30 \mathrm{~min}$ per day. The familiarization training took place in rabbits' individual cages during the first $5 \mathrm{~d}$. At the end of each familiarization session, rabbits were rewarded with a Kaytee Yogurt Dips rabbit treat. The last $2 \mathrm{~d}$ of familiarization training took place outside the individual cages, and rabbits were fully restrained. On the seventh day, a local ophthalmic anesthetic (proparacaine hydrochloride) was applied to the left eye so that a 6-0 nylon suture loop could be placed in the temporal margin of the nictitating membrane (NM).

The conditioning apparatus consisted of eight separate sound-attenuating chambers, permitting up to eight rabbits to be trained simultaneously. A speaker mounted to the wall of each chamber delivered a $1-\mathrm{kHz}, 85-\mathrm{dB}$ tone that was used as the CS. The headpiece, affixed behind the rabbit's ears and under its muzzle, held a plastic tube to deliver a 3-psi corneal-directed airpuff US and a minitorque potentiometer (San Diego Instruments) to measure the rabbit's NM/eyeblink response. Elastic eyelid retractors kept the rabbit's eye open. The potentiometer was secured to the NM via a lever and the nylon suture loop. Analog output from the potentiometer was digitized, stored, and analyzed using an IBM PC-compatible system (Chen and Steinmetz 1998). This system also controlled the timing and presentation of the stimuli. For all experiments, the inter-trial interval was randomized and ranged between 20 and $30 \mathrm{sec}$. A single session lasted $\sim 45$ min and consisted of 90 trials.

In the delay eyeblink conditioning paradigm, a 1-kHz tone was the CS. CS intensity was $85 \mathrm{~dB}$ SPL, and the duration of the tone CS was $700 \mathrm{msec}$ for the $600-\mathrm{msec}$ paradigm and $850 \mathrm{msec}$ for the 750-msec paradigm. The CS was followed 600 or $750 \mathrm{msec}$ after its onset by a 100-msec, 5-psi corneal airpuff US. The CS and US coterminated. In the trace eyeblink conditioning paradigm; the duration of the tone CS was 200 msec followed by a 400-msec blank "trace" period for the 600-msec paradigm; and the CS duration was $250 \mathrm{msec}$ followed by a $500-\mathrm{msec}$ blank "trace" period for the 750-msec paradigm. The 100-msec corneal airpuff US onset 600 or 750 msec after CS onset. The rabbits received 10 training sessions ( $5 \mathrm{~d}$ per week for $2 \mathrm{wk}$, excluding weekends). In the explicitly unpaired procedure, rabbits received the same treatment as in the paired procedure, with the exception that the tone CS and the airpuff US were never paired. For this condition, a $1-\mathrm{kHz}, 85-\mathrm{dB}$ SPL, 850-msec tone and a 100-msec, 5-psi corneal airpuff were used. On each unpaired trial, rabbits received either a tone-alone presentation or an airpuff-alone presentation. Fortyfive trials of each stimulus type were presented in a randomized format during each 45 -min session.

Changes in the position of the NM detected by the potentiometer were processed and stored in 3-msec bins by the computer. The program recorded a response when the NM moved a minimum of $0.5 \mathrm{~mm}$. A CR was recorded if the response occurred between 25 and $600 \mathrm{msec}$ or between 25 and $750 \mathrm{msec}$ after the onset of the CS. An UR alone was recorded if the response took place $>750$ msec after the onset of the CS. In both paradigms, CR and UR amplitudes were taken as a measure of response magnitude. A trial was eliminated if NM activity crossed the response threshold within $100 \mathrm{msec}$ prior to the onset of the CS. The criterion for learning was defined as eight consecutive CRs in a block of nine trials, with at least $40 \%$ of all trials within a training session as CRs.

\section{Acknowledgments}

We thank Renee Procopio and Steve Purcell for their assistance with rabbit familiarization training and behavioral testing. This research was supported by a grant from the National Institute on Aging, 1 R01 AG21925.

\section{References}

Andersen, B.B., Gundersen, H.J., and Pakkenberg, B. 2003. Aging of the human cerebellum: A stereological study. J. Comp. Neurol. 466: 356-365.

Berger, T.W. and Thompson, R.F. 1978. Neuronal plasticity in the limbic system during classical conditioning of the rabbit nictitating membrane response. I. The hippocampus. Brain Res. 145: 323-346.

Berger, T.W., Alger, B.E., and Thompson, R.F. 1976. Neuronal substrate of classical conditioning in the hippocampus. Science 192: 483-485.

Bickford, P.C., Hoffer, B.J., and Freedman, R. 1985. Interaction of norepinephrine with Purkinje cell responses to cerebellar afferent inputs in aged rats. Neurobiol. Aging 6: 89-94.

Canli, T., Detmer, W.M., and Donegan, N.H. 1992. Potentiation or diminution of discrete motor unconditioned responses (rabbit eyeblink) to an aversive Pavlovian unconditioned stimulus by two associative processes: Conditioned fear and a conditioned diminution of unconditioned stimulus processing. Behav. Neurosci. 106: $498-508$.

Chen, G. and Steinmetz, J.E. 1998. A general-purpose computer system for behavioral conditioning and neural recording experiments. Behav. Res. Methods, Instrum. Comput. 30: 384-391. 
Christian, K.M. and Thompson, R.F. 2003. Neural substrates of eyeblink conditioning: Acquisition and retention. Learn. Mem. 11: 427-455.

Coffin, J.M. 1993. "Age-related differences in classical conditioning: An investigation of morphological and distributional correlates." Ph.D. thesis, Temple University, Philadelphia, PA.

Disterhoft, J.F. and McEchron, M.D. 2000. Cellular alterations in hippocampus during acquisition and consolidation of hippocampus-dependent trace eyeblink conditioning. In Eyeblink classical conditioning: Animal models, Vol. 2 (eds. D.S. Woodruff-Pak and J.E. Steinmetz), pp. 313-334. Kluwer Academic Publishers, Boston, MA.

Disterhoft, J.F., Coulter, D.A., and Alkon, D.L. 1986. Conditioning-specific membrane changes of rabbit hippocampal neurons in vitro. Proc. Natl. Acad. Sci. 83: 2733-2737.

Garcia, K.S., Steele, P.M., and Mauk, M.D. 1999. Cerebellar cortex lesions prevent acquisition of conditioned eyelid responses. $J$. Neurosci. 19: 10940-10947.

Graves, C.A. and Solomon, P.R. 1985. Age related disruption of trace but not delay classical conditioning of the rabbit's nictitating membrane response. Behav. Neurosci. 99: 88-96.

Green, J.T. and Steinmetz, J.E. 2005. Purkinje cell activity in the cerebellar anterior lobe after rabbit eyeblink conditioning. Learn. Mem. 12: 260-269.

Green, J.T. and Woodruff-Pak, D.S. 2000. Eyeblink classical conditioning in aging animals. In Eyeblink classical conditioning: Animal models, Vol. 2 (eds. D.S. Woodruff-Pak and J.E. Steinmetz), pp. 155-178. Kluwer Academic Publishers, Boston, MA.

Kaneko, T. and Thompson, R.F. 1997. Disruption of trace conditioning of the nictitating membrane response in rabbits by central cholinergic blockade. Psychophysiology 131: 161-166.

Kim, J.J., Clark, R.E., and Thompson, R.F. 1995. Hippocampectomy impairs the memory of recently, but not remotely, acquired trace eyeblink conditioned responses. Behav. Neurosci. 109: 195-203.

Kornforst-Collins, M.A. and Disterhoft, J.A. 1998. Lesions of the caudal area of rabbit medial prefrontal cortex impair trace eyeblink conditioning. Neurobiol. Learn. Mem. 69: 147-162.

Larsen, J.O., Skalicky, M., and Viidik, A. 2000. Does long-term physical exercise counteract age-related Purkinje cell loss? A stereological study of the rat cerebellum. J. Comp. Neurol. 428: 213-222.

Marcos, J.L. and Redondo, J. 1999. Effects of CS-US interval modification on diminution of the unconditioned response in electrodermal classical conditioning. Biol. Psychol. 50: 191-201.

Moyer, J.R., Deyo, R.A., and Disterhoft, J.F. 1990. Hippocampectomy disrupts trace eye-blink conditioning in rabbits. Behav. Neurosci. 104: $243-252$.

Moyer, J.R., Power, J.M., Thompson, L.T., and Disterhoft, J.F. 2000. Increased excitability of aged rabbit CA1 neurons after trace eyeblink conditioning. J. Neurosci. 20: 5476-5482.

Pakaprot, N. and Thompson, R.F. 2005. Effect of muscimol in trace eyeblink conditioning memory: Program No. 197.9. In Abstract viewer/itinerary planner. Society for Neuroscience, Washington, DC.

Port, R.L., Romano, A.G., Steinmetz, J.E., Mikhail, A.A., and Patterson, M.M. 1986. Retention and acquisition of classical trace conditioned responses by rabbits with hippocampal lesions. Behav. Neurosci. 100: $745-752$.

Powell, D.A., Buchanan, S.L., and Hernandez, L.L. 1981. Age-related changes in classical (Pavlovian) conditioning in the New Zealand albino rabbits. Exp. Aging Res. 7: 453-465.

Powell, D.A., Skaggs, H., Churchwell, J., and McLaughlin, J. 2001. Posttraining lesions of the medial prefrontal cortex impaired performance of Pavlovian eyeblink conditioning but have no effect on concomitant hear rate changes in rabbits (Oryctolagus cuniculus). Behav. Neurosci. 115: 1029-1038.

Rogers, J., Silver, M.A., Shoemaker, W.J., and Bloom, F.E. 1980. Senescent changes in a neurobiological system: Cerebellar Purkinje cell electrophysiology and correlative anatomy. Neurobiol. Aging 1: $3-11$.

Rogers, J., Zornetzer, S.F., and Bloom, F.E. 1981. Senescent pathology of cerebellum: Purkinje neurons and their parallel fiber afferents. Neurobiol. Aging 2: 15-25.

Rogers, J., Zornetzer, S.F., Bloom, F.E., and Mervis, R.E. 1984. Senescent microstructural changes in the rat cerebellum. Brain Res. 292: 23-32.
Rose, G.M., Ong, V.S., and Woodruff-Pak, D.S. 2007. Efficacy of Mem 1003, a novel calcium channel blocker, in delay and trace eyeblink conditioning in older rabbits. Neurobiol. Aging 28: 766-773.

Schmaltz, L.W. and Theios, J. 1972. Acquisition and extinction of a classically conditioned response in hippocampectomized rabbits (Oryctolagus cuniculus). J. Comp. Physiol. Psychol. 79: 328-333.

Schneiderman, N. 1966. Interstimulus interval function of the nictitating membrane response of the rabbit under delay versus trace conditioning. J. Comp. Physiol. Psychol. 62: 397-402.

Schreurs, B.G. 2003. Classical conditioning and modification of the rabbit's (Oryctolagus cuniculus) unconditioned nictitating membrane response. Behav. Cogn. Neurosci. Rev. 2: 83-96.

Solomon, P.R. and Groccia-Ellison, M.E. 1996. Classic conditioning in aged rabbits: Delay, trace, and long-delay conditioning. Behav. Neurosci. 110: 427-435.

Solomon, P.R., Vander Schaaf, E.R., Thompson, R.F., and Weisz, D.J. 1986. Hippocampus and trace conditioning of the rabbit's classically conditioned nictitating membrane response. Behav. Neurosci. 100: $729-744$

Solomon, P.R., Pomerleau, D., Bennett, L., James, J., and Morse, D.L. 1989. Acquisition of the classically conditioned eyeblink response in humans over the lifespan. Psychol. Aging 4: 34-41.

Takehara, K., Kawahara, S., and Kirino, Y. 2003. Time-dependent reorganization of the brain components underlying memory retention in trace eyeblink conditioning. J. Neurosci. 23: 9897-9905.

Thompson, R.F., Berger, T.W., and Berry, S.D. 1980. Brain mechanisms of learning. In Neural mechanisms of goal-directed behavior and learning (eds. R.F. Thompson et al.), pp. 221-239. Academic Press, New York.

Thompson, L.T., Moyer, J., James, R., and Disterhoft, J.F. 1996. Trace eyeblink conditioning in rabbits demonstrates heterogeneity of learning ability both between and within age groups. Neurobiol. Aging 17: 619-629.

Weible, A.P., McEchron, M.D., and Disterhoft, J.F. 2000. Cortical involvement in acquisition and extinction of trace eyeblink conditioning. Behav. Neurosci. 114: 1058-1067.

Weisz, D.J. and McInerney, J. 1990. An associative process maintains reflex facilitation of the unconditioned nictitating membrane response during the early stages of training. Behav. Neurosci. 104: $21-27$.

Weisz, D.J. and Walts, C. 1990. Reflex facilitation of the rabbit nictitating membrane response by an auditory stimulus as a function of interstimulus interval. Behav. Neurosci. 104: 11-20.

Woodruff-Pak, D.S. 2006. Stereological estimation of Purkinje neuron number in C57BL/6 mice and its relation to associative learning. Neuroscience 141: 233-243.

Woodruff-Pak, D.S. and Jaeger, M.E. 1998. Predictors of eyeblink classical conditioning over the adult age span. Psychol. Aging 13: $193-205$.

Woodruff-Pak, D.S. and Thompson, R.F. 1988. Classical conditioning of the eyeblink response in the delay paradigm in adults aged 18-83 years. Psychol. Aging 3: 219-229.

Woodruff-Pak, D.S., Lavond, D.G., and Thompson, R.F. 1985. Trace conditioning: Abolished by cerebellar nuclear lesions but not lateral cerebellar cortex aspirations. Brain Res. 348: 249-260.

Woodruff-Pak, D.S., Lavond, D.G., Logan, C.G., and Thompson, R.F. 1987. Classical conditioning in 3-, 30-, and 45-month-old rabbits: Behavioral learning and hippocampal unit activity. Neurobiol. Aging 8: 101-108.

Woodruff-Pak, D.S., Li, Y.-T., Hinchliffe, R.M., and Port, R.L. 1997. Hippocampus in delay eyeblink classical conditioning: Essential for nefiracetam amelioration of leaning in older rabbits. Brain Res. 747: 207-218.

Woodruff-Pak, D.S., Jaeger, M.E., Gorman, C., and Wesnes, K.A. 1999. Relationships among age, CS-US interval, and neuropsychological test performance. Neuropsychology 13: 90-102.

Woodruff-Pak, D.S., Vogel III, R.W., and Wenk, G.L. 2001. Galantamine: Effect on nicotinic receptor binding, acetylcholinesterase inhibition, and learning. Proc. Natl. Acad. Sci. 98: 2089-2094.

Received December 17, 2006; accepted in revised form February 8, 2007. 


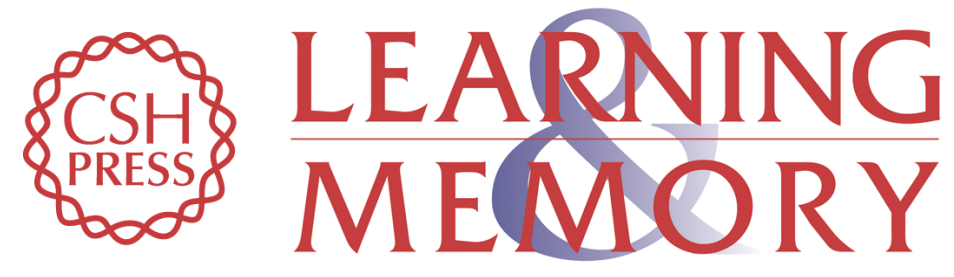

\title{
Effects of paradigm and inter-stimulus interval on age differences in eyeblink classical conditioning in rabbits
}

\author{
Diana S. Woodruff-Pak, Susan E. Seta, LaToya A. Roker, et al.
}

Learn. Mem. 2007, 14:

Access the most recent version at doi:10.1101//m.504107

References This article cites 46 articles, 7 of which can be accessed free at:

http://learnmem.cshlp.org/content/14/4/287.full.html\#ref-list-1

License Email Alerting $\begin{aligned} & \text { Receive free email alerts when new articles cite this article - sign up in the box at the } \\ & \text { Service top right corner of the article or click here. }\end{aligned}$ 